\begin{tabular}{|c|c|c|}
\hline \multirow{3}{*}{$\begin{array}{r}\text { Case Reports in } \\
\text { Gastroenterology }\end{array}$} & \multirow{2}{*}{\multicolumn{2}{|c|}{ Case Rep Gastroenterol 2015;9:341-346 }} \\
\hline & & \\
\hline & $\begin{array}{l}\text { DOI: 10.1159/000441384 } \\
\text { Publisnea ontune: Uctober 21, } 2015\end{array}$ & $\begin{array}{l}\text { (c) } 2015 \text { The Author(s) } \\
\text { Published by S. Karger AG, Basel } \\
1662-0631 / 15 / 0093-0341 \$ 39.50 / 0 \\
\text { www.karger.com/crg }\end{array}$ \\
\hline & $\begin{array}{l}\text { This article is licensed under the } C \\
\text { International License (CC BY-NC) (h } \\
\text { Usage and distribution for commerci }\end{array}$ & $\begin{array}{l}\text { mons Attribution-NonCommercial } \\
\text { rger.com/Services/OpenAccessLicense) } \\
\text { equires written permission. }\end{array}$ \\
\hline
\end{tabular}

\title{
Isolated Superior Mesenteric Artery Dissection with Small Intestine Ischemia
}

\author{
Masahito Aimi ${ }^{\mathrm{a}} \quad$ Chika Amano $^{\mathrm{b}}$ Rika Yoshida ${ }^{\mathrm{c}}$ Takeshi Matsubara $^{\mathrm{d}}$ \\ Hironobu Mikami ${ }^{a}$ Daisuke Izumi ${ }^{a}$ Eiko Okimoto $^{a}$ Norihisa Ishimura $^{a}$ \\ Shunji Ishihara $^{a}$ Yoshikazu Kinoshita $^{a}$ \\ ${ }^{a}$ Second Department of Internal Medicine, and Departments of ${ }^{b}$ Functional Pathology, \\ ${ }^{c}$ Radiology and ${ }^{d}$ Digestive Surgery, Shimane University School of Medicine, Izumo-shi, \\ Japan
}

\section{Key Words}

Superior mesenteric artery dissection $\cdot$ Ischemia $\cdot$ Small intestine

\begin{abstract}
Superior mesenteric artery (SMA) dissection without aortic dissection is a rare condition, and its diagnosis is considered to be difficult. Intestinal infarction is a severe complication of the disease, which may require resection of the intestine. We present a case of isolated SMA dissection. A 53-year-old man experienced sudden pain in the abdomen while playing Japanese pinball and was admitted to our hospital due to acute abdominal symptoms of uncertain cause. Enhanced CT revealed a defect of the root of the SMA, while angiography and intravascular ultrasound findings showed dissection of the SMA wall. Conservative treatment was chosen at the time, while a part of the small intestine was eventually resected because of progressive ischemia. Although SMA dissection is a rare occurrence in cases with acute abdominal symptoms, awareness of the condition is important for differential diagnosis.
\end{abstract}

(C) 2015 The Author(s)

Published by S. Karger AG, Basel

\section{Introduction}

Isolated superior mesenteric artery (SMA) dissection was first reported by Bauersfeld [1] in 1947 and was defined as SMA wall dissection not accompanied by aortic dissection. Recently, reports concerning this rare disease have been increasing due to the widespread use of CT for the assessment of abdominal pain [2].

KARGER 125/s $\quad \begin{aligned} & \text { Masahito Aimi, MD, PhD } \\ & \text { Second Department of Internal Medicine } \\ & \text { Shimane University School of Medicine } \\ & \text { 89-1 Enya-cho, Izumo-shi, Shimane 693-8501 (Japan) } \\ & \text { E-Mail aimi@med.shimane-u.ac.jp }\end{aligned}$


Aimi et al.: Isolated Superior Mesenteric Artery Dissection with Small Intestine Ischemia

SMA dissection was reported in middle-aged men with hypertension and a smoking habit [3]. The presence of arteriosclerosis, fibromuscular dysplasia, and elastic tissue degeneration of the arterial wall were described as causes of SMA dissection by some investigators [4]. Enhanced CT is useful as initial imaging study for the patients presenting with severe abdominal pain since it can detect various pathological conditions including arterial dissection, although arteriography provides more specific information [4]. Various types of treatments such as conservative, endovascular, and surgical treatments have been reported with some success. However, a widely accepted treatment strategy has not been established because of the rarity of the disease.

SMA dissection is an uncommon condition and may cause gut ischemia as well as deteriorate the clinical course of affected patients. Therefore, it is considered to be one of the most important diseases for a differential diagnosis in the case of acute abdominal pain. We report a case of SMA dissection that was difficult to diagnose, but was later successfully treated by resection of the small intestine.

\section{Case}

A 53-year-old man had a sudden onset of abdominal pain and vomiting while playing Japanese pinball. He visited a nearby clinic and received a subcutaneous injection of butylscopolamine $20 \mathrm{mg}$; however, the abdominal symptoms did not improve, and he visited our hospital $2 \mathrm{~h}$ after the initial onset. Vital signs were stable on arrival (body temperature $36.0^{\circ} \mathrm{C}$, blood pressure $125 / 70 \mathrm{~mm} \mathrm{Hg}$, and pulse rate 70 beats $/ \mathrm{min}$ ), though the patient had a cold sweat and reported nausea. Laboratory studies showed elevated levels of leukocytes $(14,720 / \mu \mathrm{l})$ and lactate dehydrogenase $(306 \mathrm{U} / \mathrm{l})$. Aspartate transaminase and alanine aminotransferase values were 32 and $38 \mathrm{U} / \mathrm{l}$, respectively. His abdomen was flat and soft, and there was tenderness around the navel without peritoneal signs. Bowel sounds were normal and not metallic. He could not lie in a supine position because of his pain and remained in a right lateral position. No niveau was seen on X-ray findings of the abdomen. CT revealed wall thickness in the upper small intestine, suggesting the possibility of ileitis. He was admitted to the emergency unit with acute abdominal pain of uncertain cause in order to observe the clinical course.

The patient was subcutaneously administered metoclopramide and pentazocine $15 \mathrm{mg}$ for the abdominal symptoms. Despite our recommendation to stay in the hospital, he was discharged the next day due to family problems, though the peripheral leukocyte count and C-reactive protein level were elevated to $20,010 / \mu \mathrm{l}$ and $4.7 \mathrm{mg} / \mathrm{dl}$, respectively. After returning home, vomiting and abdominal pain continued, and the patient visited the gastroenterology unit of our hospital on the third day after onset. An examination at that time showed that the abdomen was flat and soft without peritoneal irritation signs, but the patient was admitted again to the gastroenterology ward due to continuous inflammatory response (leukocyte count $10,780 / \mu \mathrm{l}$, C-reactive protein $10.66 \mathrm{mg} / \mathrm{dl}$ ). Other laboratory findings were within normal ranges (aspartate transaminase $22 \mathrm{U} / \mathrm{l}$, alanine aminotransferase $29 \mathrm{U} / \mathrm{l}$, and lactate dehydrogenase $172 \mathrm{U} / \mathrm{l})$.

Following admission, an abdominal CT with contrast enhancement was performed, which revealed wall thickness of the small intestine and a contrast filling defect in the root of the SMA (fig. 1). We made a diagnosis of SMA thrombosis and considered emergency treatment, as a portion of the small intestine was not enhanced. As a result, abdominal angiography was performed on the same day. Digital subtraction angiography showed a false lumen at the proximal SMA and stenosis of the secondary jejunal branch, which was consid- 
Aimi et al.: Isolated Superior Mesenteric Artery Dissection with Small Intestine Ischemia

ered to be a feeder to the small intestine with ischemia (fig. 2). Subsequently, intravascular ultrasonography was performed after selecting the true lumen by use of a microwire catheter. The flap structure was demonstrated by intravascular ultrasonography and considered to show signs of arterial wall dissection. Up to $50 \%$ of the true lumen in the proximal SMA was found to be obliterated. Neither dilatation nor stent placement was chosen, since blood supply to all branches of the SMA was considered to be maintained following the angiography procedure.

The patient again complained of severe abdominal pain on the fourth day. Abdominal CT with contrast enhancement was performed to detect possible redissection or necrosis of the intestine. We could not rule out necrosis of the intestine due to ischemia shown on CT findings and decided to perform laparoscopic surgery.

First, the intra-abdominal condition was observed, and no evidence of bloody ascites, inflamed peritoneal membrane, or intestinal adhesion was found. On the other hand, a $30-\mathrm{cm}$ region of poor peristalsis was found in the small intestine $40 \mathrm{~cm}$ from the anal side of the ligament of Treitz (fig. 3). No arterial beating was observed in the region of the small intestine, and the color of the serosa was whitish. Based on these findings, resection of part of the small intestine was considered necessary. The mucosal side of the resected specimen was black and had a blistered appearance, with fibrin spread through part the specimen. Microscopic histopathological imaging of the region showed hemorrhage and congestion extending to all layers, as well as necrotic changes with inflammatory cell infiltration in the submucosal layer, which was compatible with hemorrhagic necrotic jejunitis.

The patient demonstrated a good clinical course after surgery, and antihypertensive drugs were started. He was discharged on postoperative day 17. A follow-up enhanced CT examination showed narrowing of the false lumen of the SMA and no new dissection.

\section{Discussion}

The present case highlighted two important clinical issues. Partial ischemia of the small intestine caused by SMA dissection must be considered for patients with undifferentiated severe abdominal pain, and enhanced CT should be performed in the early stage.

Partial ischemia of the small intestine indicates the possibilities of SMA dissection. Stenosis of the true lumen due to compression from a false lumen can lead to progression of ischemia in cases of arterial dissection. In our patient, CT findings showed partial ischemia of the small intestine due to severe stenosis of the secondary ileal branch. Such dissections have been reported to be as long as $38.0 \pm 15.1 \mathrm{~mm}$ at onset [3]. Therefore, if the dissection extends to the branch with a narrow lumen, the area of the small intestine supplied by the feeder can easily become ischemic. On the other hand, if an embolism caused by thrombus occurs in the SMA, the long segment of the small intestine will become ischemic. Therefore, the length of the involved small intestine is considered to be important to differentiate SMA dissection from SMA thrombosis. It is necessary take into account the possibility of SMA dissection when partial ischemia is found in patients with undifferentiated abdominal pain.

Enhanced CT should be performed in the early stage for a patient with unexplained severe abdominal pain. Contrast-enhanced CT findings are reported to be more useful than those obtained with plain CT to evaluate an existing lesion, intestinal wall thickness, and ascites [5], as plain CT results can mislead to a diagnosis of SMA dissection [4]. Reported characteristic CT findings of SMA dissection include thrombosis of a false lumen, an intimal flap, an enlarged SMA diameter, increased attenuation of fat around the SMA, and hematoma in the mesentery with hemorrhagic ascites $[6,7]$. However, it should be noted that not all 
Aimi et al.: Isolated Superior Mesenteric Artery Dissection with Small Intestine Ischemia

cases necessarily have an intimal flap, and some show only an enlarged SMA diameter and increased attenuation of the fat around the SMA [8]. Morris et al. [9] reported that angiography following a CT examination clearly showed SMA dissection. In the present case, we were not able to make a definitive diagnosis based on the first enhanced CT examination and only reached our final decision based on subsequent SMA angiography. Thus, enhanced CT followed by abdominal angiography should be done for patients with unexplained severe abdominal pain, as appropriate. Others recently reported that CT angiography is useful for the diagnosis of SMA dissection, because dissection can be more readily diagnosed compared with conventional angiography $[3,10]$. We recommend that conventional angiography be performed only for patients who may require endovascular treatment in the future.

In conclusion, partial ischemia of the small intestine in cases with explained abdominal pain indicates the possibility of SMA dissection. Contrast-enhanced CT should be considered in the early stage for an accurate diagnosis. Although SMA dissection is relatively rare in cases with acute abdominal symptoms, awareness of the condition is important for differential diagnosis.

\section{Statement of Ethics}

The authors have no ethical conflicts to disclose.

\section{Disclosure Statement}

There are no potential conflicts of interest to disclose in association with this study.

\section{References}

1 Bauersfeld S: Dissecting aneurysm of the aorta; a presentation of 15 cases and a review of the recent literature. Ann Intern Med 1947;26:873-889.

-2 Akuzawa N, Seki H, Oku Y, Totsuka M, Hatori T, Imai K, Kitahara Y, Aoki J, Tashiro M, Kurabayashi M: Three cases of spontaneous isolated dissection of the superior mesenteric artery. J Emerg Med 2015;48:e111e116.

-3 Satokawa H, Takase S, Seto Y, Yokoyama H, Gotoh M, Kogure M, Midorikawa H, Saito T, Maehara K: Management strategy of isolated spontaneous dissection of the superior mesenteric artery. Ann Vasc Dis 2014;7:232-238.

-4 Watring NJ, Smith CM, Stokes GK, Counselman FL: Spontaneous superior mesenteric artery (SMA) dissection: an unusual case of abdominal pain. J Emerg Med 2010;39:576-578.

-5 Miyamoto N, Sakurai Y, Hirokami M, et al: Endovascular stent placement for isolated spontaneous dissection of the superior mesenteric artery: report of a case. Radiat Med 2005;23:520-524.

-6 Wagenhäuser MU, Sagban TA, Witte M, Duran M, Schelzig H, Oberhuber A: Isolated dissection of the superior mesenteric artery treated using open emergency surgery. World J Emerg Surg 2014;9:47.

-7 Suzuki S, Furui S, Kohtake H, Sakamoto T, Yamasaki M, Furukawa A, Murata K, Takei R: Isolated dissection of the superior mesenteric artery: CT findings in six cases. Abdom Imaging 2004;29:153-157.

-8 Kusakabe J, Kobayashi H, Miki A, Uryuhara K, Okada N, Kaihara S, Masai Y, Miyahara T, Hosotani R: A case of isolated dissection of the superior mesenteric artery treated by percutaneous stent placement (in Japanese). Jpn J Gastroenterol Surg 2012;45:434-441.

-9 Morris JT, Guerriero J, Sage JG, Mansour MA: Three isolated superior mesenteric artery dissections: update of previous case reports, diagnostics, and treatment options. J Vasc Surg 2008;47:649-653.

10 Furukawa H, Moriyama N: Spontaneous dissection of the superior mesenteric artery diagnosed on multidetector helical CT. J Comput Assist Tomogr 2002;26:143-144. 


\begin{tabular}{rl|l} 
Case Reports in & & \multicolumn{2}{c}{$\begin{array}{l}\text { Case Rep Gastroenterol 2015;9:341-346 } \\
\text { Gastroenterology }\end{array}$} & $\begin{array}{l}\text { ○ } 2015 \text { The Author(s). Published by S. Karger AG, Basel } \\
\text { www.karger.com/crg }\end{array}$ \\
\cline { 2 - 3 } & DOI: 10.1159/000441384 & \\
\cline { 2 - 3 }
\end{tabular}

Aimi et al.: Isolated Superior Mesenteric Artery Dissection with Small Intestine Ischemia

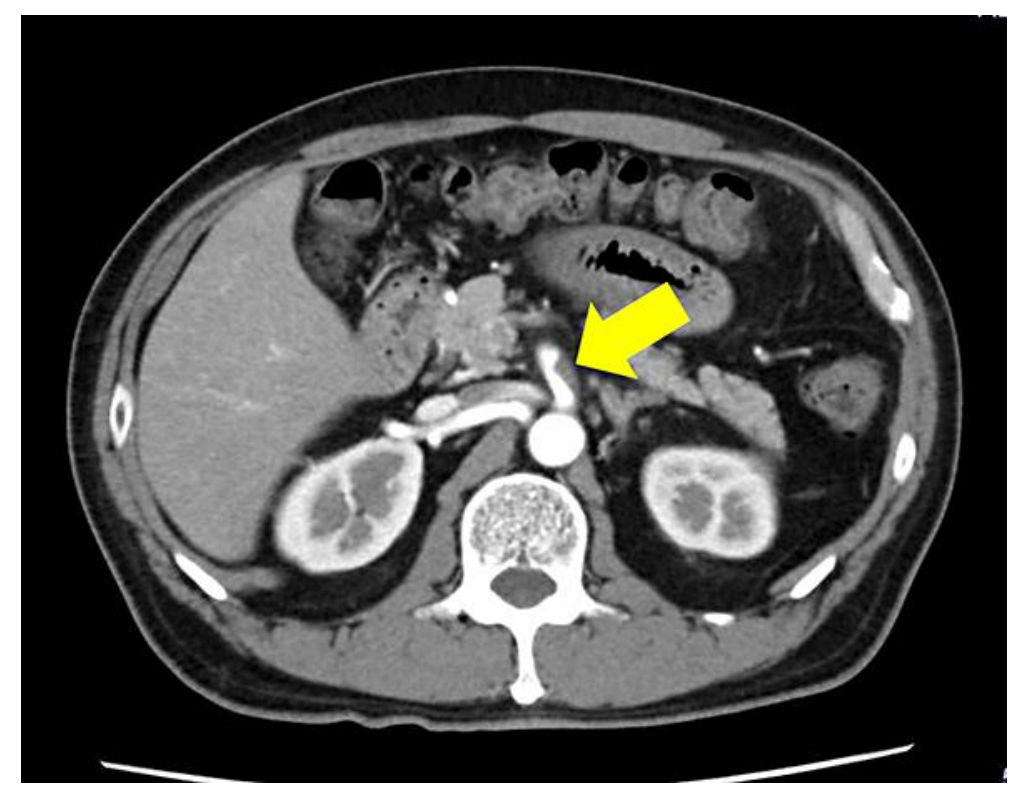

Fig. 1. Contrast-enhanced CT imaging. Partial narrowing of the proximal portion of the SMA is shown (arrow).

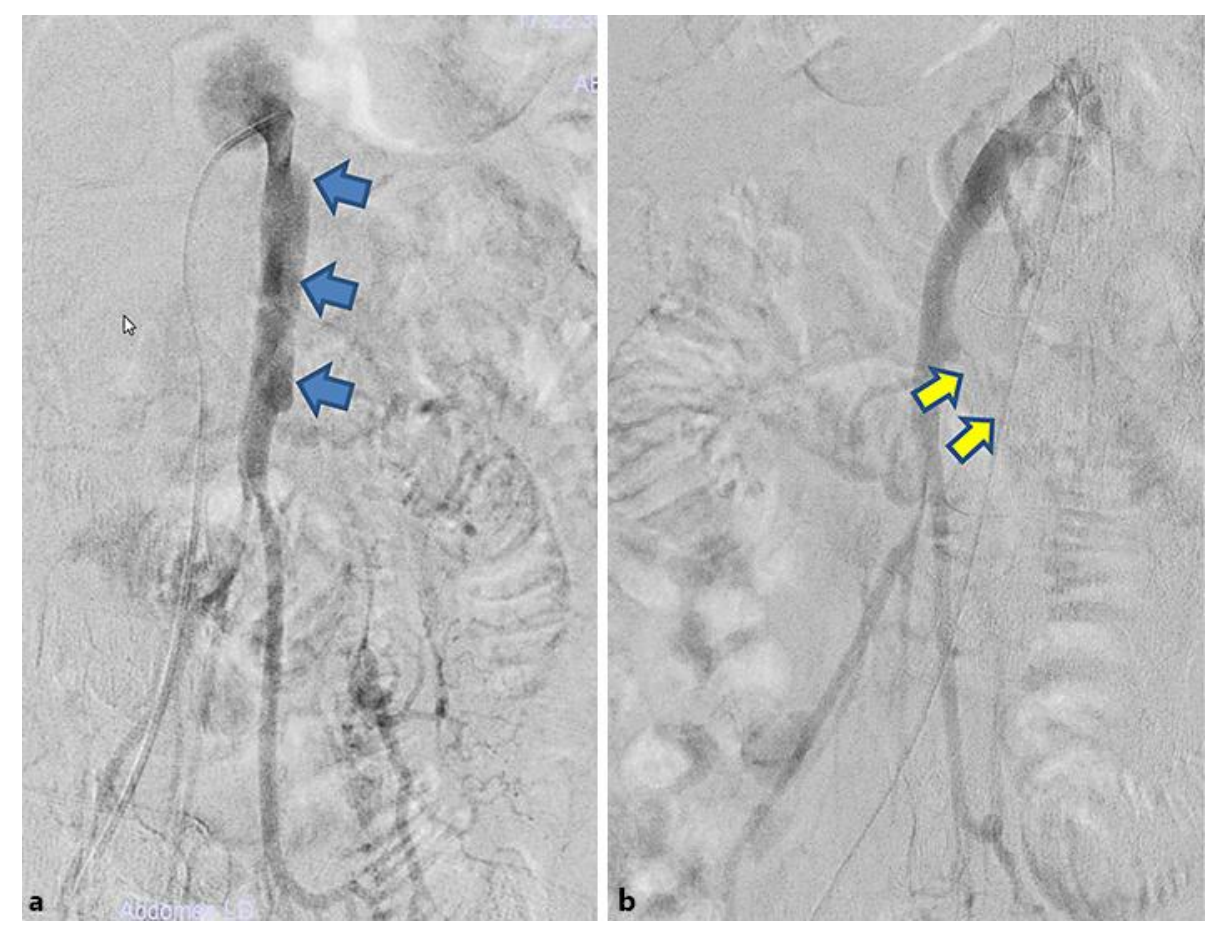

Fig. 2. Digital subtraction angiography. a Contrast enhancement suggesting a false lumen in the trunk of the SMA (arrows). b Severe stenosis of the secondary jejunal branch (arrows). 
Case Reports in
Gastroenterology

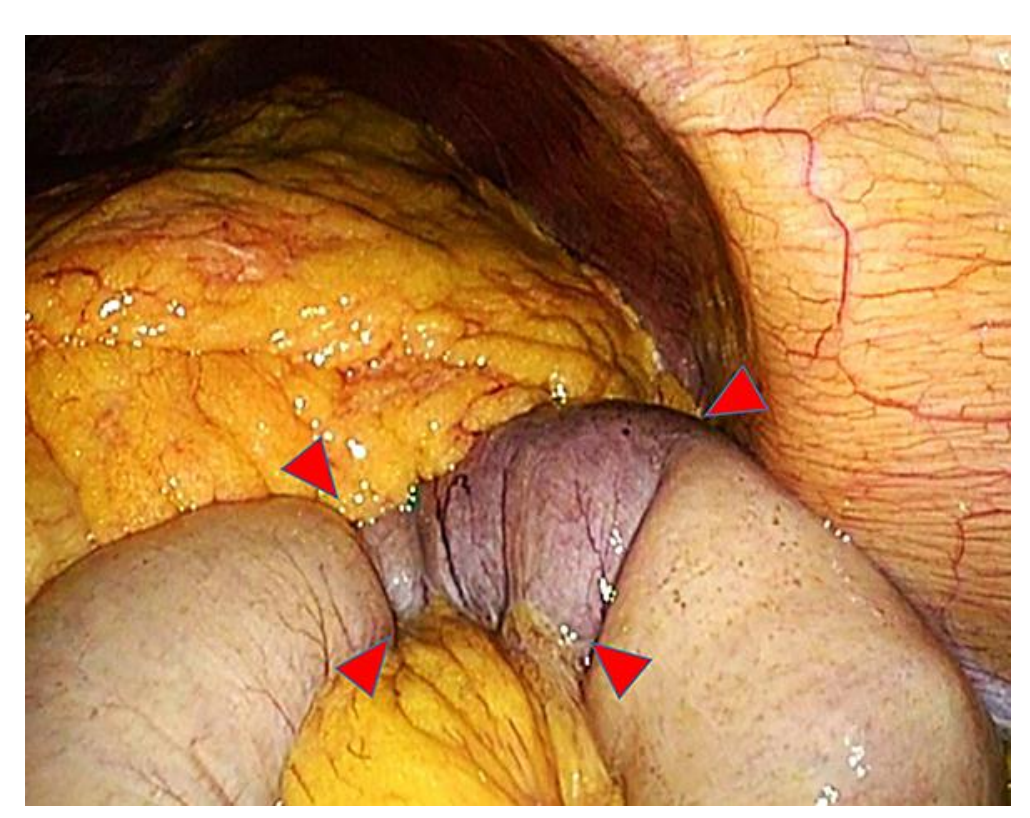

Fig. 3. During laparoscopic surgery, the ileal loop had a dark violet appearance (arrowheads), and poor

peristalsis was also found.

\begin{tabular}{l|l}
\hline Case Rep Gastroenterol 2015;9:341-346 \\
\hline DOI: 10.1159/000441384 & $\begin{array}{l}\text { c } 2015 \text { The Author(s). Published by S. Karger AG, Basel } \\
\text { www.karger.com/crg }\end{array}$ \\
\hline
\end{tabular}

Aimi et al.: Isolated Superior Mesenteric Artery Dissection with Small Intestine Ischemia 